Published in final edited form as:

Arthritis Care Res (Hoboken). 2013 April ; 65(4): 585-593. doi:10.1002/acr.21874.

\title{
Measuring IIIness Behavior in Patients with Systemic Sclerosis
}

\author{
Erin L. Merz, MA ${ }^{1}$, Vanessa L. Malcarne, $\mathrm{PhD}^{1,2}$, Scott C. Roesch, $\mathrm{PhD}^{1,2}$, Roozbeh Sharif, \\ MD ${ }^{3,4}$, Brock E. Harper, MD ${ }^{4}$, Hilda T. Draeger, MD ${ }^{5}$, Emilio B. Gonzalez, MD ${ }^{4}$, Deepthi K. \\ Nair, MS ${ }^{3}$, Terry A. McNearney, MD ${ }^{4,}$, Shervin Assassi, MD, MS $^{3}$, and Maureen D. Mayes, \\ MD, MPH $^{3}$ \\ ${ }^{1}$ SDSU/UCSD Joint Doctoral Program in Clinical Psychology, University of Texas Health Science \\ Center at Houston, Houston, Texas \\ ${ }^{2}$ Department of Psychology, San Diego State University, University of Texas Health Science \\ Center at Houston, Houston, Texas \\ ${ }^{3}$ Division of Rheumatology, University of Texas Health Science Center at Houston, Houston, \\ Texas \\ ${ }^{4}$ Division of Rheumatology, University of Texas Medical Branch, Galveston, Texas \\ ${ }^{5}$ Division of Rheumatology, University of Texas Health Science Center at San Antonio
}

\section{Abstract}

Objective-Illness behaviors (cognitive, affective, and behavioral reactions) among individuals with systemic sclerosis (SSc) are of clinical concern due to relationships between these behaviors and physical and mental-health quality of life such as pain and symptoms of depression. Selfreport measures with good psychometric properties can aid in the accurate assessment of illness behavior. The Illness Behavior Questionnaire (IBQ) was designed to measure abnormal illness behaviors; however, despite its long-standing use, there is disagreement regarding its subscales. The goal of the present study was to evaluate the validity of the IBQ in a cohort of patients with SSc.

Methods-Patients with SSc $(N=278)$ completed the IBQ at enrollment to the Genetics versus ENvironment In Scleroderma Outcome Study (GENISOS). Structural validity of previously derived factor solutions was investigated using confirmatory factor analysis. Exploratory factor analysis was utilized to derive $\mathrm{SSc}$-specific subscales.

Results-None of the previously derived structural models were supported for SSc patients. Exploratory factor analysis supported a SSc-specific factor structure with 5 subscales. Validity analyses suggested that the subscales were generally independent of disease severity, but were correlated with other health outcomes (i.e., fatigue, pain, disability, social support, mental health).

Conclusion-The proposed subscales are recommended for use in SSc, and can be utilized to capture illness behavior that may be of clinical concern.

Systemic sclerosis ( $\mathrm{SSc}$ ) is a chronic, rheumatic condition characterized by the thickening of skin and fibrosis of internal organs. It is most common among women between ages 30 and 50 but is relatively rare, with an overall prevalence of 150 to 300 cases per million [1-2]. There are two subtypes; limited cutaneous SSc is milder and has less severe organ

Corresponding Author: Vanessa L. Malcarne, SDSU/UCSD Joint Doctoral Program in Clinical Psychology, 6363 Alvarado Court, Suite 103, San Diego, CA 92120-4913, (619) 594-6495 office, (619) 594-6780 fax, malcarne @ sciences.sdsu.edu.

currently employed at Eli Lilly and Company, Indianapolis

${ }^{2}$ Correlation coefficients among factors that are $>1$ indicate that the factors are indistinguishable; therefore, model fit is unacceptable. 
involvement, diffuse cutaneous SSc is characterized by more extensive skin and organ involvement and worse prognosis [3]. Individuals with SSc report problems across multiple domains including fatigue [4], pain [5], disability [6], sleep [7], interpersonal functioning, [8], anxiety, depression [9], and more generally, physical and mental-health related quality of life [10]. There is also an increasing awareness that disease severity is inadequate for discriminating patients who are at risk for poor adjustment, suggesting a need to also emphasize psychosocial variables [6].

Illness behaviors, defined as cognitive, emotional and behavioral reactions [11], can occur in response to chronic diseases such as SSc. Although illness behavior is neutral by definition, some behaviors are more adaptive than others [12]. For example, concerns about health may encourage a patient with SSc to seek necessary medical help, or could lead to excessive doctor's visits and anxiety. It may be helpful to divulge one's feelings about their disease to others, but excessive disclosure may lead to social network problems. Such extreme responses, termed abnormal illness behavior, also include actions to maintain the sick role, or a level of disability that exceeds the given pathology [12].The Illness Behavior Questionnaire (IBQ) is a widely used tool that was developed to measure these reactions [13]. The IBQ contains 62 yes/no items, including all 14 items of the Whiteley Index [14]. The history and development of the IBQ have been discussed elsewhere [15]. The IBQ was developed in a relatively small sample $(N=100)$ of pain clinic patients using principal components analysis with varimax rotation, which yielded 7 subscales $^{1}$ : General Hypochondriasis (anxious health-related concern), Disease Conviction (belief that a "real" disease is present), Psychological vs. Somatic Functioning (tendency to somaticize), Denial (tendency to attribute life stress to physical problems), Affective Inhibition (inability to express personal feelings to others), Affective Disturbance (anxiety, depression), and Irritability (anger, friction). The IBQ has been associated with physical and psychological quality of life across a variety of conditions such as healthcare utilization and disability [16], post-operative outcomes [17], health-related quality of life [18], psychopathology [19], anxiety [20], depression [21], fatigue [4, 22], pain [23], and social support [24].

Unfortunately the psychometric properties of the IBQ have not been well-established. The original factor structure [13] has been shown to be unstable across studies. Although internal structure is only one consideration when evaluating a measure's overall performance [25], this does suggest that the interpretability of the IBQ for other disease groups may be uncertain. Several alternate structures have been proposed [26-28], although most researchers utilize the original subscales. The original subscales have been used in patients with cancer [29], gastroesophogeal reflux disease [17], myocardial infarction [30], stroke [16], lupus [31], fibromyalgia [32], osteoarthritis, rheumatoid arthritis [33], chronic fatigue syndrome, multiple sclerosis [34], and back pain [23, 35].

There are several possibilities as to why the IBQ has not been well-replicated in different populations and diseases. The IBQ may have been overfactored [26], which can lead to unreliable or split factors [36]. Because IBQ items are binary, poor factor specification is especially problematic given the high influence of item-level error on a factor [26]. It is also plausible that previous samples were not large enough to reproduce the IBQ's structure. The original subscales were developed using data from 100 patients, although the structure did later replicate in 1,578 pain and psychiatric patients [37]. Another study [26] also used a relatively small sample $(N=200)$, but others reported findings from large $(N=675-1,061)$ samples [27-28]. Another consideration is that the factorial instability is due to a disconnect between methodological and practical considerations, and the challenges inherent to

\footnotetext{
${ }^{1}$ Pilowsky and Spence [13] initially used items 1-52 in their analysis and removed 22 items due to poor loadings. Items 53-62 were written afterwards based on face validity and added to the subscales to improve internal consistency reliability. Thus, only 40 of the 62 items were ultimately used in the original 7 subscales.
} 
measuring complex psychological constructs [25]. Alternately, it has been suggested that the IBQ's inconsistent factor structure is due to disease-specific illness behaviors unique to the physical process, treatment, and functional and social implications [15]. Accordingly, some items may be more or less relevant for a given disease. For example, the Disease Conviction subscale may not apply to individuals with an identified pathology; it is reasonable that a person with a diagnosed disease would indeed have a strong belief that they have a disease. Thus, a new research agenda has been proposed [15, 27], which entails investigating the need for disease-specific subscales to best capture the experiential, cognitive, and behavioral aspects of a given illness. Because understanding illness behavior may aid in providing total clinical care, so that patients with maladaptive illness behaviors may be identified and offered additional intervention or referral, it would be beneficial to determine whether the IBQ can be used in patients with SSc.

\section{Objective}

The study's first aim was to evaluate the various IBQ factor structures. If the internal structure is not upheld, which could suggest problems with previously derived solutions for patients with SSc, the second aim of the study was to uncover a plausible factor structure specifically for SSc. The third aim was to establish convergent and divergent validity of the subscales derived from the best fitting model, via correlations of derived subscales with disease severity, and other quality of life variables. We predicted that the dimensions of the IBQ would have little to no correlation with disease severity, as has been shown with other psychosocial variables [6]. We also predicted that greater endorsement of illness behaviors would be related to worse fatigue, pain, disability, social support, and mental health, as has been previously demonstrated [4, 16, 20-24].

\section{Materials and Methods}

\section{Participants}

This investigation utilized data provided by participants from the $G$ enetics versus ENvironment In Scleroderma Outcome Study (GENISOS), a prospective early-disease (within 5 years of onset) cohort study that represents collaboration among the University of Texas Health Science Center at Houston, the University of Texas Medical Branch at Galveston, and the University of Texas-Health Science Center at San Antonio. Enrollment is ongoing. Data are collected annually via a clinical exam and survey packet during regular outpatient visits, and intermittently as inpatient services (as needed) at the hospitals staffed by the clinician-investigators. Patients with SSc who lived within the geographic catchment area of one of the three centers were recruited from the rheumatology faculty clinics, the county hospital, and chapters of the Scleroderma Foundation [38]. Participants had to be at least 18 years old.

\section{Procedure}

Baseline data from the GENISOS study were used [38]. IRB approval was obtained at all participating institutions, including San Diego State University and University of California, San Diego for analysis of archival data. All participants gave written informed consent. Participants received clinical examinations by the physician investigators including evaluations of clinical manifestations (e.g., sclerodactyly, skin thickening, Raynaud's phenomenon, gastrointestinal involvement), comorbidities, an electrocardiogram, a chest radiograph, and blood samples and completed a packet of psychosocial measures. 


\section{Measures}

IIIness Behavior Questionnaire (IBQ [13])-The IBQ is a 62-item self-report measure designed to measure illness behavior (see the supplementary appendix for basic item data). Using a yes/no format, respondents indicate whether an item describes them, with 'abnormal' behaviors being scored 1 point.

Modified Rodnan Skin Score (mRSS [39])-The mRSS total score is an established indicator of skin disease severity in SSc calculated by measuring the extent and severity of skin thickening on 17 body surfaces by palpation on a 4-point scale $(0=$ uninvolved to $3=$ severe thickening). Higher scores indicate greater severity.

Forced Vital Lung Capacity (\% predicted FVC)—Percent predicted FVC is a validated measure for severity of SSc-related interstitial lung disease [40]. It indicates the ratio of the volume of air that the study subject can forcibly exhale after a maximum inspiration to the same volume in age, gender, weight, height, and ethnicity matched unaffected controls. All pulmonary measurements met criteria outlined by the American Thoracic Society/European Respiratory Society, and were reviewed by a pulmonologist. Lower scores indicate greater severity of SSc-related interstitial lung disease.

Fatigue Severity Scale (FSS [41])—The FSS is a widely used 29-item self-report questionnaire wherein respondents rate the extent of their agreement with statements regarding their level of fatigue on a Likert scale $(1=$ completely disagree to $7=$ completely agree). It has demonstrated adequate test-retest reliability, discriminant validity, and convergent validity [41]. The FSS yields an overall score and 4 factor-analytically derived subscales. The total score, in which higher total scores represent more severe global fatigue, was used in the current study. Internal consistency $(\alpha=.90)$ was good.

Medical Outcomes Study Short-Form 36 (SF-36 [42])-The SF-36 is a 36-item selfreport health-related quality of life measure that yields 8 factor-analytically derived subscales and 2 composite scores of physical and mental health. The questions follow a variety of response formats, scoring algorithms are required for generating the subscales. It is reliable and valid for SSc [43]. The Bodily Pain $(\alpha=.87)$ and Mental Health $(\alpha=.79)$ subscales were utilized. Higher scores indicate better domain-related quality of life.

Modified Health Assessment Questionnaire (mHAQ [44])-The mHAQ is a 8-item self-report index of overall disability. Respondents rate their functional ability to perform tasks on a 4-point scale $(0=$ without any disability to $3=$ unable to do). It has been validated for use in SSc [44-45], and shown to have a one-factor structure [46]. Internal consistency $(a=.91)$ was good in the current sample. Higher scores reflect greater disability.

Interpersonal Support Evaluation List (ISEL [47])—The ISEL is a widely-used 40item self-report measure of perceived social support wherein respondents rate whether a statement is "probably true" or "probably false" based on their experience. The ISEL yields four subscales and a total score of overall support which has been supported using confirmatory factor analysis [48]. The total score was used for the current study and demonstrated good internal consistency $(a=.87)$. Higher scores indicate better social support.

\section{Data analysis}

Factor analysis was conducted to achieve aims one and two. Theory-driven confirmatory factor analysis (CFA) was utilized to evaluate previously derived IBQ factor structures. If CFA models do not provide sufficient fit, it is reasonable to follow up with exploratory 
factor analysis (EFA [50]). Data-driven EFA was conducted to explore alternate structures by estimating the number of underlying latent variables within the data and thus identifying SSc-specific subscales.

Because the IBQ contains binary data, traditional factor analytic techniques are inappropriate, as the assumptions of linearity and normality are violated [51]. A tetrachoric correlation matrix, wherein it is assumed that a normally distributed continuous latent variable underlies the "truncated" binary items should therefore be used [51]. Moreover, ordinary least-squares and maximum likelihood estimation approaches are not recommended due to dependencies and systematic residuals among observed variables [52]. Consequently, a tetrachoric correlation matrix with a weighted least-squares means and variance adjusted (WLSMV) estimation procedure in MPlus 6.1 [53] that is robust to non-normal and nonindependent data was used. Internal consistency for all factors in all models was evaluating using the Kuder-Richardson-20 formula.

Evaluation of model fit-For CFA and EFA, it is recommended that samples are at least 200[54], although samples greater than 250 are preferred for binary data [55]. The current sample is near the low end of this desired range, but does meet these recommendations. Because $\chi^{2}$ tests may not be suitable to determine model fit, descriptive fit indices were also calculated [56]. The Comparative Fit Index (CFI; [57]) and Root Mean Square Error of Approximation (RMSEA; [58]) were used, as other descriptors (e.g., Root Mean Square Residual [59]) are unfit for binary data [55]. A model fit well if CFI values were $\geq .95$ and RMSEA values were $\leq .05$ based on widely accepted guidelines [55].

Exploratory analysis-Previous researchers have used different combinations of items in their exploratory factor analyses of the IBQ. In the original study, items 1-52 were included in the analysis, and items 53-62 were added afterwards to increase the number of items per subscale and to improve internal consistency [13]. Prior and Bond [27] used a similar strategy by including items 1-52 in their analysis, and later adding items 54 and 59, based on face validity and internal consistency. Zonderman, Heft and Costa [28] found that the solutions for two analyses (the first on items 1-52, the second on items 1-63) were identical and reported the latter solution. Main and Waddell [26] removed 25 items due to poor reliability and/or incidence, leaving 37 items for the analyses. Given the heterogeneity of approaches, and Pilowsky's [37] suggestion that the IBQ may be particularly useful as an item pool, all 62 items were analyzed in the EFA so that results were not reliant on face validity. Models with 1-7 factors were tested to reflect the various numbers of dimensions found in previous studies. A factor needed at least 3 items (preferably 4) to reduce the likelihood of over-factoring [26]. In EFA, items with loadings of the strict criterion of $>.40$ was used to inhibit errors in factor estimation. Cross-loadings were determined as loadings greater than half of the primary loading. Although underfactoring (i.e., including too few factors in a model) has not typically been a criticism of the IBQ, it can lead to problems, such as the combination of multiple factors [36]; therefore, the pattern matrix was also inspected for interpretability. Items derived from the factor analysis were further evaluated for their contribution to the internal consistency of their subscale. Based on recommendations for decreasing redundancy among subscale items, items were retained if their removal from a subscale resulted in decreased internal consistency, and eliminated if internal consistency was unchanged upon removal [49]. Subscale intercorrelations were then evaluated; models with intercorrelations with high multicollinearity $(r>.7)$ were considered unsuitable. 


\section{Results}

Descriptive characteristics are available in Table 1. Skin thickening $(t[274]=-13.79$; diffuse $M=22.03$ [11.10]; limited $M=6.74$ [5.39]) and forced vital lung capacity ( $t$ [262] = 2.65; diffuse $M=80.09$ [20.71]; limited $M=87.16$ [22.36]) indicated greater disease severity in the diffuse subtype ( $p$ s $<.001$ and $<.01$, respectively).

\section{CFAs of original and alternate models}

First, CFA was used to examine the model fit of the 7 dimensions comprised of 40 items, as suggested by Pilowsky and Spence [13]. Internal consistencies were poor (.200 - .697); only Affective Disturbance (.759) was reliable. Model fit was poor statistically, $\chi^{2}[719, N=$ $278]=1048.04, p<.001$, and descriptively, $\mathrm{CFI}=.893$, RMSEA $=.041$. Interfactor correlations ranged from $\left|.20-1.06^{2}\right|$, suggesting high redundancy among factors. Because internal consistency and solution were both poor, most dimensions were inadmissible, thus alternate structures were considered.

The 6 dimensions comprised of 47 IBQ items as suggested by Zonderman and colleagues [28] were tested first. Internal consistency was better (.632 - .796). Model fit was poor statistically, $\chi^{2}[1019, N=278]=1538.46, p<.001$, and descriptively, CFI = .871, RMSEA $=.043$. Interfactor correlations ranged from $|.21-.81|$.

The 6 dimensions comprised of 33 IBQ items as suggested by Main and Waddell [26] were tested next. Internal consistencies ranged from .566 to .814 . Model fit was poor statistically, $\chi^{2}[492, N=278]=1093.12, p<.001$, and descriptively, CFI $=.782$, RMSEA $=.066$. Interfactor correlations ranged from $|.32-.72|$.

Finally, the 3 dimensions comprised of 31 IBQ items as suggested by Prior and Bond [27] were tested. Internal consistency was good $(.733-.805)$; however, model fit was poor statistically, $\chi^{2}[431, N=278]=804.70, p<.001$, and descriptively, CFI $=.893$, RMSEA $=.056$. Interfactor correlations ranged from $|.69-.74|$.

\section{Exploratory analysis of IBQ items ${ }^{3}$}

Because none of the models fit adequately, EFA was utilized to determine if a better model could be derived (Table 2). The 4-factor model was the first to meet the descriptive fit criteria, therefore models 4-7 were evaluated for interpretability. Inspection of the simple structure of these models showed an adequate number of items on the 4- and 5-factor models. For the 6- and 7-factor models, several dimensions yielded only 2 to 3 items. Given the issues of over-factoring [26], these models were not evaluated further.

Both the 4- and 5-factor models were reviewed on the basis of simple structure and interpretability. Both contained 3 identical factors. However, the largest factor from the 4factor model was split into 2 meaningful factors in the 5-factor model, suggesting that the 4factor model was underfactored. At this point, 33 items were removed due to insufficient loadings or cross-loadings. Each factor was then further refined based on internal consistency, as described above. The final solution used 23 items. The factor loadings are shown in Table 3.

\section{SSc-specific subscales of the IBQ}

Table 4 describes the subscales, and items shared with subscales from previous solutions. Intercorrelations among the SSc subscales $(r \mathrm{~s}=.00$ to .38$)$ were reasonable.

\footnotetext{
${ }^{3}$ In the exploratory analysis, raw data (not reverse scored) were analyzed.
} 
Symptom Bother-Three items that loaded onto this subscale were removed as they did not improve internal consistency. Thus, the first subscale retained the 5 best items out of the 8 that met the interpretability criteria. Higher scores indicate greater intensity and life interference of disease-related symptoms. Internal consistency (.778) was adequate.

Health Worry-One item that loaded onto the second subscale was removed as it did not improve internal consistency. Thus, the second subscale retained the 5 best items out of the 6 that met interpretability criteria. Higher scores indicate that a respondent is more preoccupied with health in general. Internal consistency (.725) was adequate.

Interpersonal Functioning-Two items that loaded onto the third subscale were removed as they did not improve internal consistency. Thus, the third subscale retained the 5 best items out of the 7 that met interpretability criteria. Higher scores indicate more interpersonal problems. Internal consistency (.720) was adequate.

Other Life Worries-Four items loaded onto the fourth subscale. Higher scores indicate a greater number of non-illness problems. Internal consistency (.715) was adequate.

Affective Inhibition-Four items loaded onto the fifth subscale. Higher scores reflect greater difficulty expressing emotion to others. Internal consistency (.662) for this subscale was weaker.

\section{Relationships of subscales to health outcomes}

Correlations between the subscales and other measures were performed to establish convergent and divergent validity (Table 5). As predicted, the proposed subscales were not generally associated with disease severity. As predicted, the subscales were related to fatigue, pain, disability, social support, and mental health in the expected directions. Higher scores on the subscales were associated with worse outcomes, with stronger relationships among related domains (e.g., relationships between symptom bother and pain, or between affective inhibition and social support).

\section{Discussion}

The current study expands on efforts to create a useful measure that characterizes illness behaviors by examining the psychometric properties of the IBQ [13] in patients with SSc. None of the previous solutions adequately fit data from patients with SSc. Failing to replicate the factor structure of a measure is one element that may call its performance into question, thus, the approach became exploratory. The physiological and psychological aspects of specific diseases vary widely, thus it is reasonable for different diseases to have different factor structures and resultant subscales for the IBQ [15, 55]. Thus, only items that were meaningful for SSc patients were included to ensure sharper measurement of the relevant aspects of illness behavior for SSc. On the basis of a number of statistical and theoretical decisions, a SSc-specific structure was derived. The proposed subscales comprised illness-related (Symptom Bother, Health Worry), social (Interpersonal Functioning), and affective (Other Life Worries, Affective Inhibition) domains.

Internal consistency of the subscales was acceptable; although Affective Inhibition was lower but satisfactory, given the small number of items and exploratory nature of the study [60]. Although higher internal consistencies have been reported for longer subscales [27], this is unsurprising given that items were added after factor analysis based on face validity, with the specific intention of increasing internal reliability. Shorter forms that are 
sufficiently valid and reliable to achieve measurement objectives are generally preferable in clinical contexts.

The validity analyses suggested that SSc-specific subscale scores were generally unrelated to skin thickness and pulmonary function. This suggests that disease severity only partially explains illness behavior. Fatigue, pain, disability, social support, and mental health were generally associated with the subscales, such that greater endorsement of the illness behavior domains was predictive of poorer outcomes. Taken together, these findings suggest that these subscales provide an acceptable assessment of illness behavior in SSc. However, score interpretation should be considered in the larger context of a patient's current physical status and psychological comorbidities.

Given the rarity of SSc, a notable strength of the current study is the large, representative sample of patients. However, there were some limitations. Only cross-sectional data were utilized. The sample size was on the low end of recommendations for latent variable analyses. Despite these limitations, this study provides preliminary support for the utility of the IBQ for patients with SSc. Future work should focus on confirming this factor structure in a different sample of patients with SSc, and on comparing the measurement model between diffuse and limited subtypes. Additionally, researchers and clinicians should begin building more integrative models of illness behavior, with attention to the physical, psychological and social aspects of SSc to enhance total patient care. Within such a framework, clinicians will be better equipped to identify at-risk patients to implement appropriate interventions to target problematic illness behaviors [61], underscoring the need for a reliable and valid screening tool.

In sum, this study evaluated the factorial validity of the IBQ in a sample of patients with SSc derived from the GENISOS cohort. The original factor structure of the IBQ was not supported among, providing one piece of evidence that may call the factor structure into question. Therefore, a SSc-specific factor structure was uncovered, which demonstrated convergent and divergent validity. These subscales offer clinicians a relatively concise way to identify patients who may benefit from additional intervention.

\section{Supplementary Material}

Refer to Web version on PubMed Central for supplementary material.

\section{Acknowledgments}

Grant support: This study was funded by the National Institute of Health (NIH/NIAMS) Center of Research Translation (CORT) in Scleroderma P50AR054144 (Mayes); NIH-KL2RR024149 and K23AR061436 (Assassi).

\section{References}

1. Barnes J, Mayes MD. Epidemiology of systemic sclerosis: Incidence, prevalence, survival, risk factors, malignancy, and environmental triggers. Curr Opin Rheumatol. 2012; 24:165-70. [PubMed: 22269658]

2. Mayes MD, Lacey JV, Beebe-Dimmer J, Gillespie BW, Cooper B, Laing TJ, et al. Prevalence, incidence, survival, and disease characteristics of systemic sclerosis in a large US population. Arthritis Rheum. 2003; 48(8):2246-55. [PubMed: 12905479]

3. Medsger, TA. Classification, prognosis. In: Clements, PJ.; Furst, DE., editors. Systemic sclerosis. 2. New York, NY: Lippincott, Williams \& Wilkins; 2004. p. 17-28.

4. Assassi S, Leyva AL, Mayes MD, Sharif R, Nair DK, Fischback M, et al. Predictors of Fatigue Severity in Early Systemic Sclerosis: A Prospective Longitudinal Study of the GENISOS Cohort. PLoS ONE. 2011; 6(10):e26061.10.1371/journal.pone.0026061 [PubMed: 22022507] 
5. Schieir O, Thombs BD, Hudson M, Boivin JF, Steele R, Bernatsky S, et al. Prevalence, severity, and clinical correlates of pain in patients with systemic sclerosis. Arthritis Care Res. 2010; 62:409-17.

6. Malcarne VL, Hansdottir I, McKinney A, Upchurch R, Greenbergs HL, Henstorf GH, et al. Medical signs and symptoms associated with disability, pain, and psychosocial adjustment in systemic sclerosis. J Rheumatol. 2007; 34:359-67. [PubMed: 17304659]

7. Frech T, Hays RD, Maranian P, Clements PJ, Furst DE, Khanna D. Prevalence and correlates of sleep disturbance in systemic sclerosis-results from the UCLA scleroderma quality of life study. Rheumatology. 2011; 50:1280-7. [PubMed: 21324979]

8. Suarez-Almazor ME, Kallen MA, Roundtree AK, Mayes M. Disease and symptom burden in systemic sclerosis: A patient perspective. J Rheumatol. 2007; 34:1718-1726. [PubMed: 17611983]

9. Legendre C, Allanore Y, Ferrand I, Kahan A. Evaluation of depression and anxiety in patients with systemic sclerosis. Joint Bone Spine. 2005; 72:408-11. [PubMed: 16214073]

10. Hudson M, Thombs BD, Steele R, Panopalis P, Newton E, Baron M. Canadian Scleroderma Research Group. Health related quality of life in systemic sclerosis: A systematic review. Arthritis Rheu. 2009; 61:1112-20.

11. Mechanic D, Volkart E. Stress, illness behavior and the sick role. Am Sociol Rev. 1961; 26:51-8.

12. Pilowsky I, Spence ND. Patterns of illness behaviour in patients with intractable pain. J Psychosom Res. 1975; 19:279-87. [PubMed: 1202213]

13. Pilowsky, I.; Spence, ND. Manual for the Illness Behaviour Questionnaire (IBQ). 2. Adelaide, South Australia: University of Adelaide; 1983.

14. Pilowsky I. Dimensions of hypochondriasis. Br J Psychiatry. 1967; 113:89-93. [PubMed: 6029373]

15. Prior KN, Bond MJ. The measurement of abnormal illness behaviour: Toward a new research agenda for the Illness Behaviour Questionnaire. J Psychosom Res. 2008; 64:245-53. [PubMed: 18291238]

16. Clark MS, Smith DS. Abnormal illness behaviour in rehabilitation from stroke. Clin Rehabil. 1997; 11:162-70. [PubMed: 9199869]

17. Hayden J, Myers JC, Jamieson GG. Analysis of illness behavior in patients after "failed" antireflux surgery. Arch Surg. 2006; 141:243-46. [PubMed: 16549688]

18. Sanchez ML, McGwin G Jr, Durán S, Fernández M, Reveille JD, Vilá LM, Alarcón GS. LUMINA Study Group. Factors predictive of overall health over the course of the disease in patients with systemic lupus erythematosus from the LUMINA cohort (LXII): use of the SF-6D. Clin Exp Rheumatol. 2009; 27:67-71. [PubMed: 19327231]

19. Hobbis IC, Turpin G, Read NW. Abnormal illness behaviour and locus of control in patients with functional bowel disorders. Br J Health Psychol. 2003; 8:393-408. [PubMed: 14614788]

20. Joyce PR, Bushnell JA, Walshe JW, Morton JB. Abnormal illness behaviour and anxiety in acute non-organic abdominal pain. Br J Psychiatry. 1986; 149:57-62. [PubMed: 3779314]

21. Fava GA, Pilowsky I, Pierfederici A, Bernardi M, Pathak D. Depressive symptoms and abnormal illness behavior in general hospital patients. Gen Hosp Psychiatry. 1982; 4:171-8. [PubMed: 7141211]

22. Burgos PI, Alarcón GS, McGwin G Jr, Crews KQ, Reveille JD, Vilá LM. Disease activity and damage are not associated with increased levels of fatigue in systemic lupus erythematosus patients from a multiethnic cohort: LXVII. Arthritis Rheum. 2009; 61:1179-86. [PubMed: 19714612]

23. Keefe FJ, Crisson JE, Maltbie A, Bradley L, Gil KM. Illness behavior as a predictor of pain and overt behavior patterns in chronic low back pain patients. J Psychosom Res. 30:543-51. [PubMed: 2945923]

24. Grassi L, Rosti G. Psychiatric and psychosocial concomitants of abnormal illness behaviour in patients with cancer. Psychother Psychosom. 1996; 65:246-52. [PubMed: 8893325]

25. Hopwood CJ, Donnellan MB. How should the internal structure of personality inventories be evaluated? Pers Soc Psychol Rev. 2010; 14:332-46. [PubMed: 20435808]

26. Main CJ, Waddell G. Psychometric construction and validity of the Pilowsky Illness Behaviour Questionnaire in British patients with chronic low back pain. Pain. 1987; 28:13-25. [PubMed: 2950364] 
27. Prior KN, Bond MJ. New dimensions of abnormal illness behaviour derived from the Illness Behaviour Questionnaire. Psychol Health. 2010; 25:1209-27. [PubMed: 20204979]

28. Zonderman AB, Heft MW, Costa PT. Does the Illness Behaviour Questionnaire measure abnormal illness behaviour? Health Psychol. 1985; 4:425-36. [PubMed: 4076118]

29. Tulipani C, Morelli F, Spedicato MR, Maiello E, Todarello O, Porcelli P. Alexithymia and cancer pain: the effect of psychological intervention. Psychother Psychosom. 2010; 79:156-63. [PubMed: 20185972]

30. Byrne DG. Psychological responses to illness and outcome after survived myocardial infarction: a long term follow-up. J Psychosom Res. 1982; 26:105-12. [PubMed: 7077542]

31. Alarcón GS, McGwin G, Uribe A, Friedman AW, Roseman JM, Fessler BJ, et al. Systemic lupus erythematosus in a multiethnic lupus cohort (LUMINA). XVII. Predictors of self-reported healthrelated quality of life early in the disease course. Arthritis Rheum. 2004; 51:465-74. [PubMed: 15188335]

32. Huber A, Suman AL, Biasi G, Carli G. Alexithymia in fibromyalgia syndrome: associations with ongoing pain, experimental pain sensitivity and illness behavior. J Psychosom Res. 2009; 66:42533. [PubMed: 19379959]

33. Ahern MJ, McFarlane AC, Leslie A, Eden J, Roberts-Thomson PH. Illness behaviour in patients with arthritis. Ann Rheum Dis. 1995; 54:245-50. [PubMed: 7763099]

34. Trigwell P, Hatcher S, Johnson M, Stanley P, House A. "Abnormal” illness behaviour in chronic fatigue syndrome and multiple sclerosis. BMJ. 1995; 311:15-8. [PubMed: 7613314]

35. Waddell G, Pilowsky I, Bond MR. Clinical assessment and interpretation of abnormal illness behaviour in lower back pain. Pain. 1989; 39:41-53. [PubMed: 2530486]

36. Fava JL, Velicer WF. The effects of overextraction on factor and component analysis. Multiv Behav Res. 1992; 27:387-415.

37. Pilowsky I. Dimensions of illness behaviour as measured by the Illness Behaviour Questionnaire: A replication study. J Psychosom Res. 1993; 37:53-62. [PubMed: 8421260]

38. Reveille JD, Fischbach M, McNearney T, Friedman AW, Aguilar MB, Lisse J, et al. Systemic sclerosis in 3 US ethnic groups: A comparison of clinical, sociodemographic, serologic, and immunogenetic determinants. Semin Arthritis Rheum. 2001; 30:332-46. [PubMed: 11303306]

39. Clements PJ, Hurwitz EL, Wong WK, Seibold JR, Mayes M, White B, et al. Skin thickness scores as a predictor and correlate of outcome in systemic sclerosis: High-dose versus low-dose penicillamine trial. Arthritis Rheum. 2000; 43:2445-54. [PubMed: 11083267]

40. Furst D, Khanna D, Matucci-Cerinic M, Clements P, Steen V, Pope J, et al. Systemic sclerosis continuing progress in developing clinical measures of response. J Rheumatol. 2007; 34:1194200. [PubMed: 17477486]

41. Schwartz JE, Jandorf L, Krupp LB. The measurement of fatigue: A new instrument. J Psychosom Res. 1993; 37:753-62. [PubMed: 8229906]

42. Ware JE, Sherbourne CD. The MOS 36-item short-form health survey (SF-36). I. Conceptual framework and item selection. Med Care. 1992; 30:473-83. [PubMed: 1593914]

43. Danieli E, Airo P, Bettoni L, Cinquini M, Antonioli CM, Cavazzana I, et al. Health-related quality of life measured by the Short Form 36 (SF-36) in systemic sclerosis: correlations with indexes of disease activity and severity, disability, and depressive symptoms. Clin Rheumatol. 2005; 24:4854. [PubMed: 15300468]

44. Poole JL, Williams CA, Bloch DA, Hollak B, Spitz P. Concurrent validity of the Health Assessment Questionnaire Disability Index in Scleroderma. Arthritis Care Res. 1995; 8:189-93. [PubMed: 7654804]

45. Poole JL, Steen VD. The use of the Health Assessment Questionnaire (HAQ) to determine physical disability in systemic sclerosis. Arthritis Care Res. 1991; 4:27-31. [PubMed: 11188583]

46. Cole JC, Motivala SJ, Khanna D, Lee JY, Paulus HE, Irwin MR. Validation of single- factor structure and scoring protocol for the Health Assessment Questionnaire-Disability Index. Arthritis Rheum. 2005; 53:536-42. [PubMed: 16082630]

47. Cohen, S.; Mermelstein, R.; Kamarck, T.; Hoberman, H. Measuring the Functional Components of Social Support. In: Sarason, I.; Sarason, B., editors. Social support: theory, research, and applications. Boston, MA: Martinus Nijhoff; 1985. p. 73-94. 
48. Brookings JB, Bolton B. Confirmatory factor analysis of the interpersonal support evaluation list. Am J Community Psychol. 1988; 16:137-47. [PubMed: 3369379]

49. Devillis, RF. Scale development: Theory and applications. 3. Thousand Oaks, CA: Sage Publications; 2012.

50. Schmitt TA. Current methodological considerations in exploratory and confirmatory factor analysis. J Psychoed Assess. 2011; 29:304-21.

51. Woods CM. Factor analysis of scales composed of binary items: Illustration with the Maudsley Obsessional Compulsive Inventory. J Psychopathol Behav Assess. 2002; 24:215-23.

52. Muthén BO, Satorra A. Technical aspects of Muthén's LISCOMP approach to estimation of latent variable relations with a comprehensive measurement model. Psychometrika. 1995; 60:489-503.

53. Muthén, LK.; Muthén, BO. Mplus Users' Guide. 6. Los Angeles, CA: Muthén \& Muthén; 19982010.

54. Schumacker, RE.; Lomax, RG. A beginner's guide to structural equation modeling. 2. Mahwah, NJ: Lawrence Erlbaum Associates; 2004.

55. Yu, CY. Doctoral dissertation. University of California; Los Angeles: 2002. Evaluating cutoff criteria of model fit indices for latent variable models with binary and continuous outcomes.

56. Millsap RE, Kwok OM. Evaluating the impact of partial factorial invariance on selection in two populations. Psychol Methods. 2004; 9:93-115. [PubMed: 15053721]

57. Bentler PM. Comparative fit indexes in structural models. Psychol Bull. 1990; 107:238-246. [PubMed: 2320703]

58. Steiger JS. Structural model evaluation and modification: An interval estimation approach. Multiv Behav Res. 1990; 25:173-80.

59. Hu LT, Bentler PM. Cutoff criteria for fit indexes in covariance structure analysis: Conventional criteria versus new alternatives. Struct Equ Modeling. 1999; 6:1-55.

60. Robinson, JP.; Shaver, PR.; Wrightsman, LS. Criteria for scale selection and evaluation. In: Robinson, JP.; Shaver, PR.; Wrightsman, LS., editors. Measures of personality and social psychological attitudes. New York, NY: Academic Press; 1991.

61. Kirmayer LJ, Looper KJ. Abnormal illness behaviour: Physiological, psychological and social dimensions of coping with distress. Curr Opin Psychiatry. 2006; 19:54-60. [PubMed: 16612180] 


\section{Significance and Innovations}

- Illness behaviors may be associated with quality of life outcomes in SSc; such behaviors have been measured in other disease populations using the Illness Behavior Questionnaire (IBQ).

- The psychometric properties of the IBQ have not been evaluated in SSc.

- Results support the use of the IBQ in SSc, and that behaviors that may be most relevant to SSc quality of life are symptom bother, health worry, interpersonal functioning, other life worries, and affective inhibition. 


\section{Table 1}

Sample characteristics.

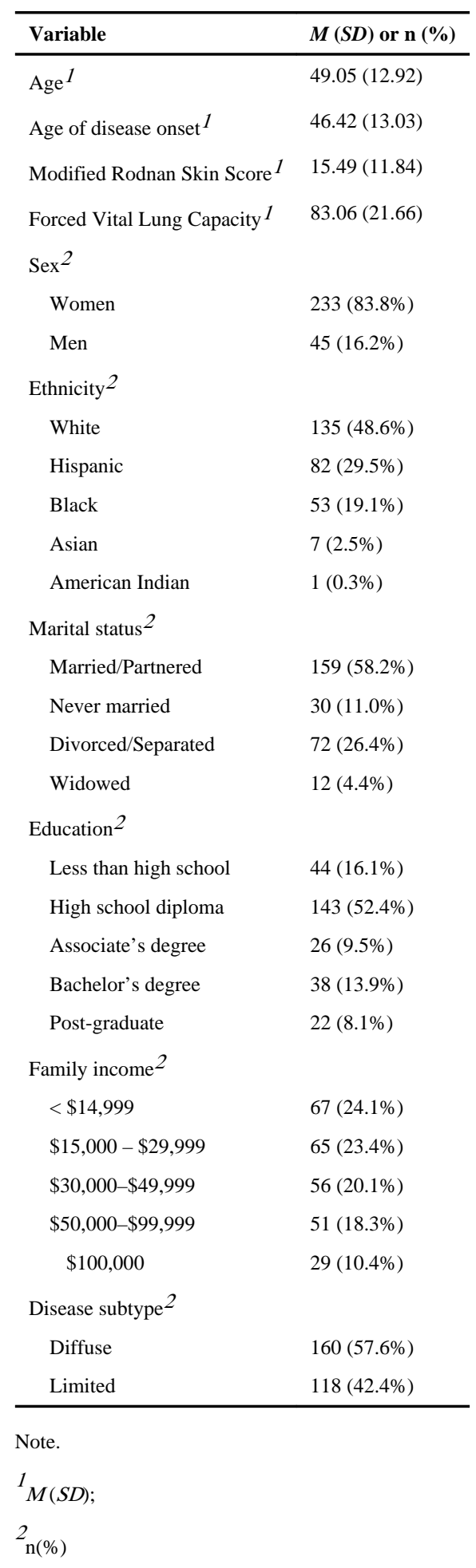




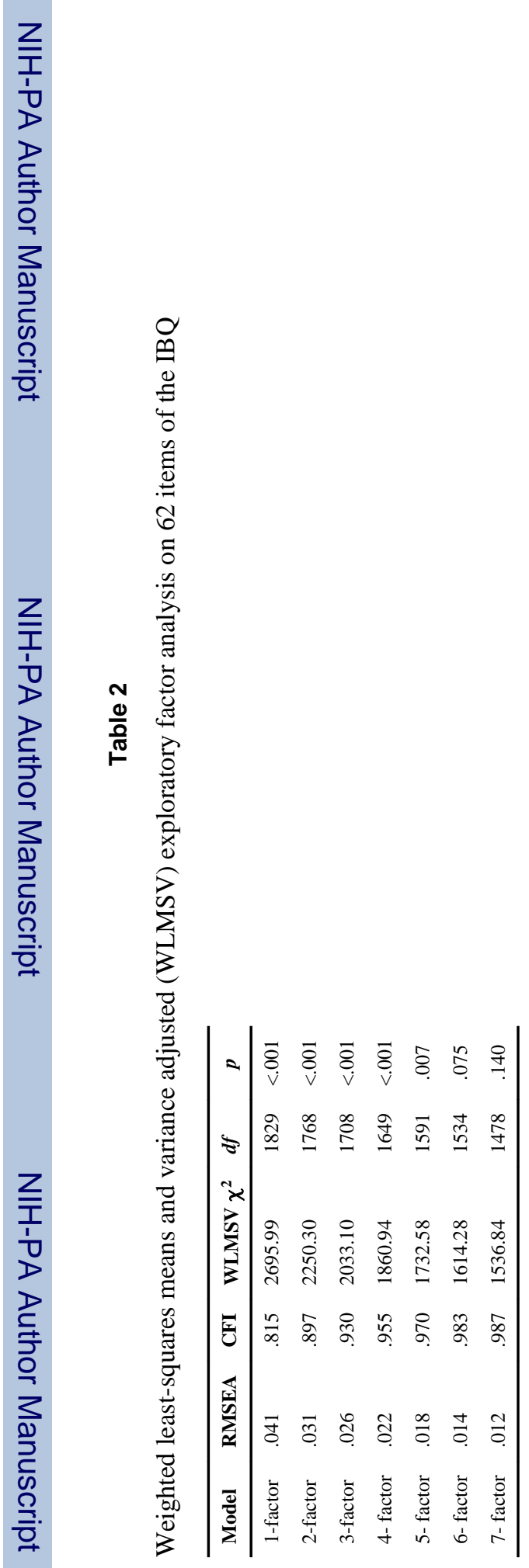




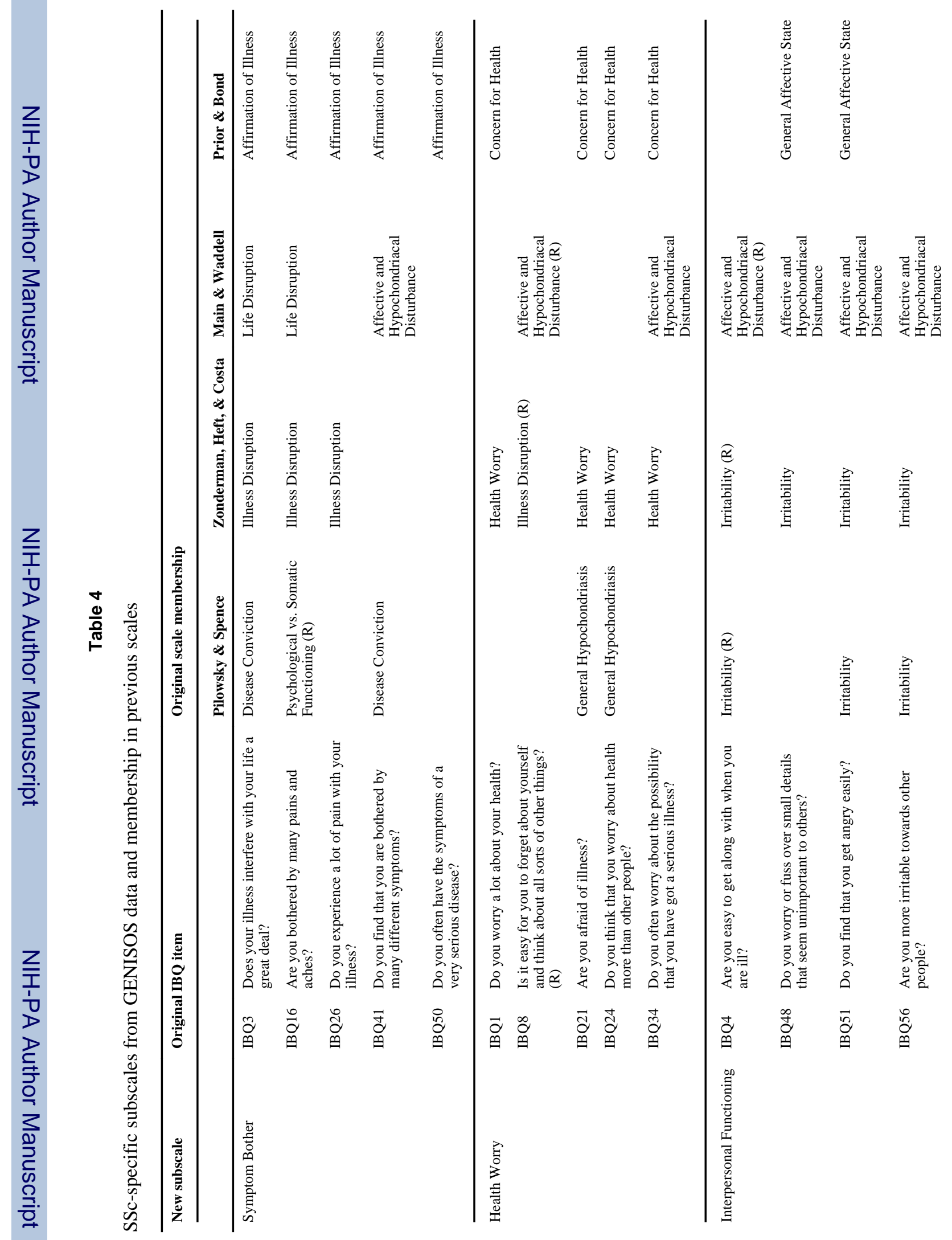


Merz et al.

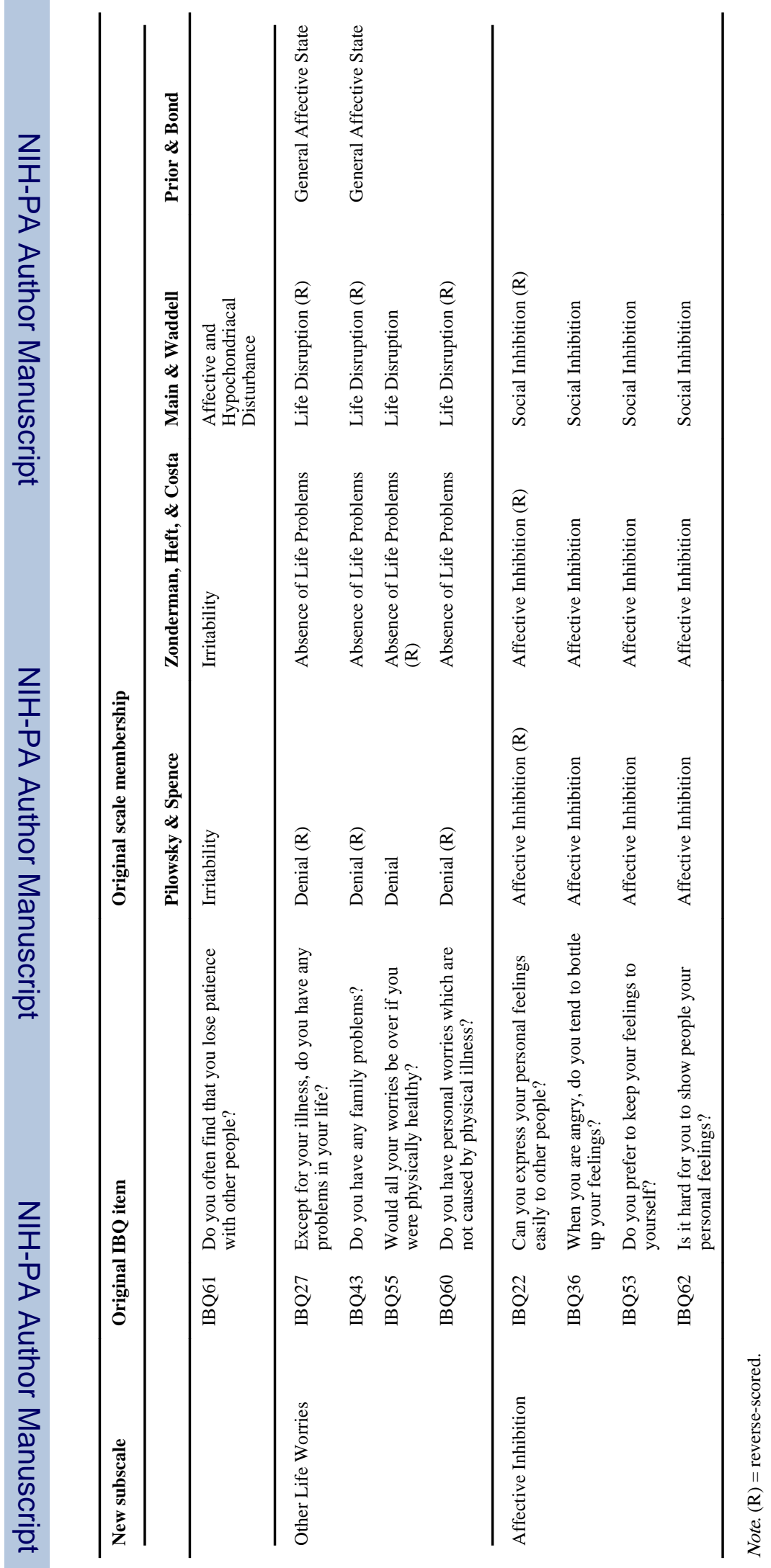

Arthritis Care Res (Hoboken). Author manuscript; available in PMC 2014 April 01. 


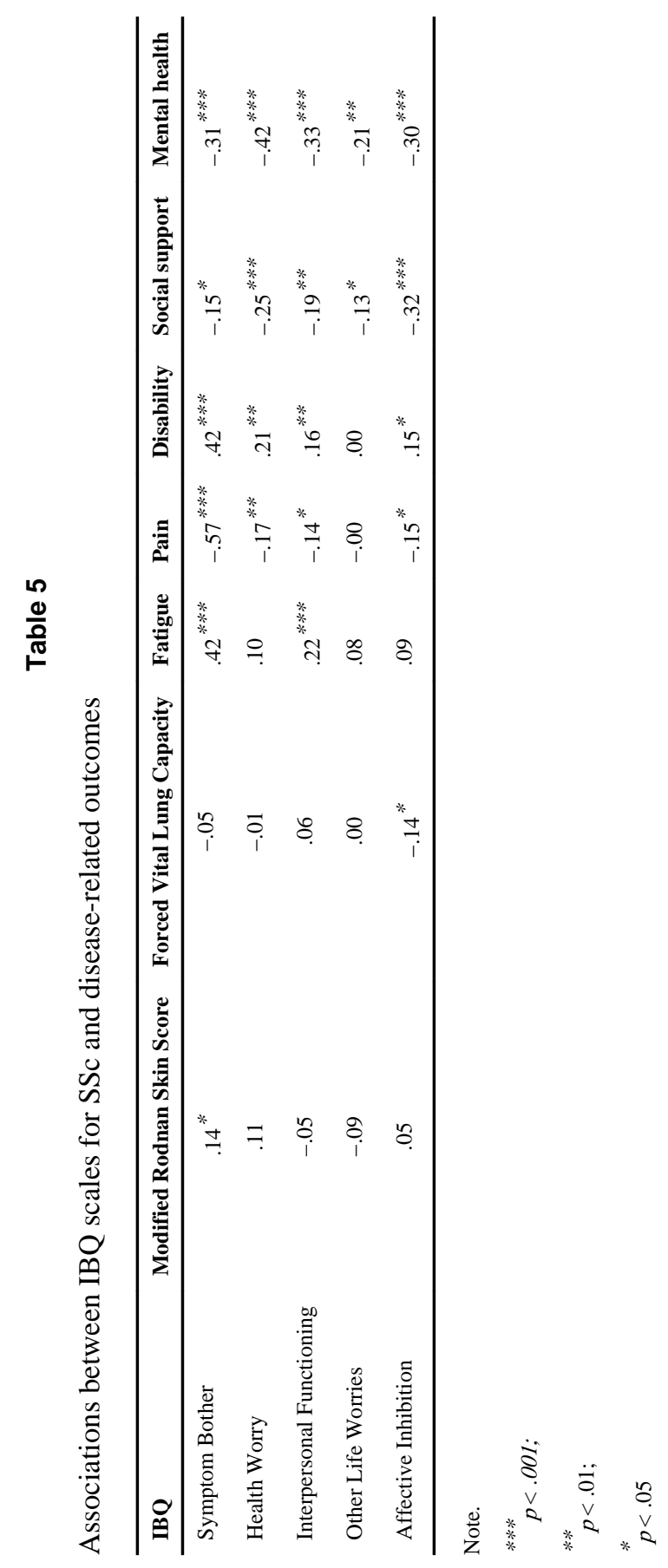

Arthritis Care Res (Hoboken). Author manuscript; available in PMC 2014 April 01. 